\title{
CYTOPROTECTIVE EFFECTS OF HONEY IN COMBINATION WITH AQUEOUS AND ETHANOL EXTRACTS FROM CHROMOLAENA ODORATA L. (EUPATORIUM ODORATUM L.) IN RATS
}

Nur Jannah MH, Mahmood AA, Sidik K and Salmah I

Department of Molecular Medicine, Faculty of Medicine, University of Malaya, 50603 Kuala Lumpur, Malaysia

\begin{abstract}
Six groups of adult Sprague-Dawley rats were orally administered with a variety of treatments to elucidate their cytoprotective effects. Absolute ethanol combined with $\mathrm{HCl}$ was used to induce gastric lesions in rats. Aqueous and ethanol extracts of Chromolaena odorata, a famous folk herb for treating skin wounds were evaluated to determine their protective effect on gastric mucosa. In this study, aqueous extract and ethanol extract of $C$. odorata were combined with honey. In addition, honey alone and honey combined with cimetidine were also evaluated. Rat stomachs were examined grossly and histologically. Results were expressed as inhibition percentage. The honey and aqueous extract combination showed the highest inhibition percentage $(72.67 \%)$ followed by honey and ethanol extract $(58.92 \%)$, honey and cimetidine $(56.55 \%)$ and the lowest was honey alone $(46.74 \%)$. However, there were no significant differences between the effects of aqueous and ethanol extracts of C. odorata and honey in promoting cytoprotective effects and this may be due to the small sample size. Nevertheless, these results suggest that $C$. odorata and honey may be beneficial in treating induced gastric mucosal injury. (JUMMEC 2006; 9(1): 7-13)
\end{abstract}

KEYWORDS: Honey, cimetidine, ulcer, Chromolaena odorata, rats

\section{Introduction}

The definition of cytoprotective effects could be interpreted as the capability of a compound to prevent the formation of gastric mucosa necrosis produced by a variety of necrotizing agents, without reducing acid secretion. The exact mechanism of gastric cytoprotective effects in maintaining the cellular integrity of the gastric mucosa that are subjected to strong irritants is unknown (I).

In humans, the gastric mucosa is often bombarded with aggressive exogenous and endogenous luminal agents. Therefore, the body has its own cytoprotective properties to retain mucosal layer integrity and reduce the frequency of developing erosions, ulcers, and hemorrhages (2).

For example, glutathione, which is abundant in the stomach, was demonstrated to be protective against ethanol-induced gastric mucosal damage by scavenging free radicals (3). Besides glutathione, prostaglandin activity (I) and activation of Protease- activated receptor-2 (PAR-2) also exert a cytoprotective effect (4).

In a healthy human stomach, an efficient equilibrium exists between the potential for gastric acid and pepsin to damage gastric mucosal cells and the ability of these gastric cells to protect themselves from injury (5). There are many reasons which lead to gastric mucosal injury that consequently caused the exposure of hydrochloric acids and pepsin to the underlying epithelial cells. It was suggested that one reason is that reactive oxygen species (ROS) can chemically induce gastric mucosal injury. Furthermore, it was investigated that ROS may cause DNA fragmentation (5).

Correspondence:

Assoc. Prof. Dr. Mahmood Ameen Abdulla

Department of Molecular Medicine

Faculty of Medicine, University of Malaya

50603 Kuala Lumpur, Malaysia

Tel: $603-79676600$

Fax: 603-7967 6600

Email: mahmood_ameend@yahoo.com 
A report suggested that natural honey is able to protect the rat stomach and also able to accelerate healing against acute ethanol- and indomethacingastric lesions (6). Another study also explained the effects of honey in gastroprotective activity. The report mentioned that the mechanism of gastroprotective properties in honey against ethanolinduced gastric haemorrhagic lesions is mediated through sulfhydryl (SH)-sensitive processes. In referring to the previous statement, it was suggested that honey has many similar features to sucralfate, which is a locally acting anti-ulcer drug. Honey and sucralfate have both been shown to deliver protection against ethanol-induced gastric haemorrhagic lesions by preventing depletion of endogenous non-protein $\mathrm{SH}$ mainly in the form of glutathione (GSH). Consequently both honey and sucralfate have the ability to inhibit vascular permeability changes and vascular damage which are induced by ethanol (7).

Besides that, the constituents of catalase in honey are able to promote protection against the toxic effects of oxygen-derived free radicals (ODFRs) and abolish the increment of endothelial cell permeability (7).

Chromolaena odorata (L) King and Robinson (formerly Eupatorium odoratum), belongs to the family Asteraceae and is a native plant of South and Central America. This species has, however, successfully spread to other warm and humid tropical regions such as South Africa, Vietnam, India, Indonesia, Malaysia, Sri Lanka and the Philippines $(8,9)$.

It is a herbaceous perennial, which grows into a big bushy herb or subshrub and can reach up to the height of three meters in open area $(8,10, I I)$. C. odorata is believed to be a poisonous plant with exceptionally high levels of nitrate, which is five to six times above the toxic level especially in the leaves and young shoots (I2). However, C. odorata is a famous herbal remedy in treating wounds. In Vietnam, the fresh leaves and extracts of the plant have been long used in treating burns, soft tissues and skin infections (I3).

Even though there are not many studies done to evaluate the use of $C$. odorata extracts in preventing ulcer, there are claims that $C$. odorata can be used as treatment for abdominal disorders. A study also showed that methanol extract of the leaves of C. odorata possess anti-inflammatory, antipyretic and antispastimodic properties. The study also established that the extract attributed to antimotility and antidiarrheal effects (14).
The leaves of $C$. odorata have the maximum amount of allelochemicals (15). A study in Vietnam showed that the aqueous extract of the leaf consisted of flavonoids (salvigenin, sakuranetin, isosakuranetin, kaempferide, betulenol, 2-5-7-3 tetra-O-methyl quercetagetin, tamarixetin, and two chalcones, odoratin, and its alcoholic compound), essential oils (geyren, bornyl acetate, beta eubeden), saponin triterpenoids, tannins, organic acids, and numerous trace substances (16).

Another study showed that the crude ethanol extract of $C$. odorata contains phenolic acids (protocatechuic, p-hydroxybenzoic, p-coumaric, ferulic and vanilic acids) and complex mixtures of lipophilic flavonoid aglycones (flavanones, flavonols, flavones and chalcones) (I7).

In this study, a comparison was made between aqueous and ethanol extracts of $C$. odorata mixed with honey to determine which method of extraction resulted in better cytoprotective effect to the gastric mucosa. Cimetidine, a $\mathrm{H}_{2}$-receptor antagonist was also mixed with honey and evaluated for its cytoprotective effect.

\section{Materials and Methods}

\section{Honey}

The honey used in this study was pure, unprocessed, unboiled and commercialized, purchased from the Faculty of Agriculture, University Putra Malaysia, Serdang, Selangor, Malaysia. The honey was filtered before use.

\section{C. odorata}

Leaves were separated from the stalk and were dried in an oven at $50^{\circ} \mathrm{C}$ for 5-7 days or until the leaves were fully dried. Then the leaves were ground. The aqueous extract of $C$. odorata was prepared by placing ground leaves in a conical flask. Sterile water was added such that for every I g of ground leaves was 20 $\mathrm{ml}$ of sterile water $(\mathrm{I}: 20)$. Then the flask containing the ingredients was left and the contents macerated for three hours on a hot plate. The ethanol extract of $C$. odorata was prepared by placing the ground leaves in a conical flask and $96 \%$ denatured ethanol was added in the proportion of I $g$ of ground leaves to $20 \mathrm{ml}$ of $96 \%$ denatured ethanol $(\mathrm{I}: 20)$. The flask containing the ingredients was then left for maceration for approximately 5-7 days at room temperature. 
Next, the crude extracts from aqueous and ethanol extractions were filtered with a filter funnel to remove the filtrate. After that, the filtered extracts were concentrated with the aid of a rotary evaporator at $60^{\circ} \mathrm{C}$. Finally, the concentrated extracts were freeze-dried to produce a powdery form of the extracts, which were stored at $-20^{\circ} \mathrm{C}$ until use.

\section{Preparation of honey in combination with C. odorata extracts and cimetidine}

Honey was combined with aqueous and ethanolic $C$. odorata extracts respectively at $(10 \% \mathrm{w} / \mathrm{w})\left(5 \mathrm{ml} \mathrm{kg}^{-1}\right)$. Cimetidine was also combined with honey at $10 \mathrm{mg} /$ I $\mathrm{ml}\left(5 \mathrm{ml} \mathrm{kg}^{-1}\right)$.

\section{Animals}

The rats were caged individually in a cylindrical stainless steel cage to avoid coprogaphy. The rats were deprived of food but allowed free access to tap water for 48 hours prior to the experiments. Water was withheld about 18 hours before the experiments. Six rats were assigned to each group and labeled as follows, normal (Group I); ulcer control (Group 2); pre-treatment with honey alone (Group 3); pretreatment with honey combined with aqueous $C$. odorata extracts (Group 4); pre-treatment with honey combined with ethanolic C. odorata extracts (Group 5 ); and pre-treatment with honey combined with cimetidine (Group 6). Thirty minutes later, I $\mathrm{ml}$ of absolute ethanol combined with $\mathrm{HCl}(0.6 \mathrm{~N} \mathrm{HCl}$ mixed with equal volume of absolute alcohol) was orally administered to each rat in Group 2, Group 3, Group 4, Group 5 and Group 6 to induce gastric ulceration. Then, 30 minutes later, all the rats were sacrificed by administrating an overdose of diethyl ether then their stomachs were removed and maintained in 10\% formalin for further gross and microscopic examination.

\section{Gross and microscopic examination}

Each stomach was cut along the greater curvature. The mucosal lesions were traced under the dissecting microscope $(\times 20)$ with the aid of square-grid eyepiece (I mm square). The ulcer index (UI) was determined as the sum of gastric lesions for each stomach and the inhibition percentage was expressed as a percentage of the control by the following formula, as earlier described (18):

Inhibition percentage (\%)

$=\left[\left(U I_{\text {ulcer control }}-U I_{\text {treated }}\right) / U I_{\text {ulcer control }}\right] \times 100$
The stomachs were then trimmed and fixed. Next, the tissues were processed, embedded in paraffin, and subsequently sectioned. The sections were stained with haematoxylin and eosin ( $\mathrm{H} \& \mathrm{E})$ and examined under light microscope at $\times 10$ and $\times 40$ magnification.

\section{Results}

\section{Group I (Normal) - Rats administered with distilled water}

Rats in this group were administered with distilled water and served as the normal control group. There were no thick black or red lines at the outer stomachs, which were observed before the stomachs were cut opened. Gross examination showed no haemorrhaging and the mucosal rugae was in normal condition. The histology results showed no red blood cells and intact mucosal cells without gastric edema. The submucosa layer appeared to be in normal condition.

\section{Group 2 (Ulcer control) - Gastric lesions produced by absolute ethanol combined with $\mathrm{HCl}$}

Oral administration of I $\mathrm{ml}$ absolute ethanol combined with $\mathrm{HCl}$ (mixed equal volume of each) to the rats produced extensive necrosis of the gastric mucosa. Thick black or red lines were visible outside the stomachs, which indicated severe gastric damage. Gross examination showed a large amount of haemorrhagic lesions confined mostly in the gastric corpus, which is the secreting region of the stomach. Histologically, necrosis involved about two-third of the mucosa layer and exfoliation of the mucosal cells was detected. Meanwhile, red blood cells were present in the gastric mucosa and edematous submucosa was discovered as well. Inflammatory exudates were also found around the mucosal layer.

\section{Group 3 - Effects of honey alone on gastric lesions produced by absolute ethanol com- bined with $\mathrm{HCl}$}

Pre-treatment with honey alone before the induction of gastric lesions by absolute ethanol combined with $\mathrm{HCl}$ showed modest cytoprotective effect to the gastric mucosa. About half of the stomach showed haemorrhagic condition. Honey inhibition of gastric lesions produced by absolute ethanol combined with $\mathrm{HCl}$ was 46.74\% (Table I). Histological examination showed the presence of red blood cells and moderate exfoliation of mucosal epithelial cells. However, the mucosa 
Table I. Tabulated results of gross examination of all oral treatment

\begin{tabular}{|c|c|c|c|c|c|c|}
\hline Group & Treatment & $\begin{array}{l}\text { No. of } \\
\text { Rats }\end{array}$ & $\begin{array}{c}\text { Ratio of Treatment } \\
\text { to Honey }\end{array}$ & Dose & $\begin{array}{c}\text { Ulcer Index } \\
\text { (Mean } \pm \text { S.E.M) }\end{array}$ & $\begin{array}{c}\text { Inhibition } \\
(\%)\end{array}$ \\
\hline I & $\begin{array}{l}\text { Normal saline } \\
\text { (normal) }\end{array}$ & 6 & - & $5 \mathrm{ml} \mathrm{kg}^{-1}$ & $9.17 \pm 3.11^{a}$ & - \\
\hline 2 & $\begin{array}{l}\text { Abs. ethanol }+\mathrm{HCl} \\
\text { (ulcer control) }\end{array}$ & 6 & - & $5 \mathrm{ml} \mathrm{kg}^{-1}$ & $1194.83 \pm 121.02^{b}$ & - \\
\hline 3 & Honey alone & 6 & - & $5 \mathrm{ml} \mathrm{kg}^{-1}$ & $636.33 \pm 26.72^{c}$ & 46.74 \\
\hline 4 & $\begin{array}{l}\text { Aqueous extract } \\
\text { C. odorata + Honey }\end{array}$ & 6 & $10 \% \mathrm{w} / \mathrm{w}$ & $5 \mathrm{ml} \mathrm{kg}^{-1}$ & $326.50 \pm 31.93^{d}$ & 72.67 \\
\hline 5 & $\begin{array}{l}\text { EtOH. extract } \\
\text { C. odorata }+ \text { Honey }\end{array}$ & 6 & $10 \% \mathrm{w} / \mathrm{w}$ & $5 \mathrm{ml} \mathrm{kg}^{-1}$ & $490.83 \pm 52.2 I^{\mathrm{cde}}$ & 58.92 \\
\hline 6 & Cimetidine + Honey & 6 & $10 \mathrm{mg} / \mathrm{l} \mathrm{ml}$ & $5 \mathrm{ml} \mathrm{kg}^{-1}$ & $519.17 \pm 12.23^{e}$ & 56.55 \\
\hline
\end{tabular}

All values are expressed as means and standard error. Mean with different superscripts are significantly different at $(P<0.05)$.

appeared to be eroded with the presence of exudates. Neutrophils were found around blood vessels of the submucosa.

\section{Group 4 - Effects of honey combined with aqueous extract of $\mathrm{C}$. odorata on gastric lesions produced by absolute ethanol com- bined with $\mathrm{HCl}$}

Pre-treatment with honey and aqueous extract of C. odorata significantly prevented the formation of gastric lesions produced by absolute ethanol combined with $\mathrm{HCl}$ at an inhibition percentage of $72.67 \%$. Gross examination showed mild haemorrhage lesions with the ulcer index of $326.50 \pm 31.93$ (Table I). Histological examination showed intact mucosa layers with mild exfoliation of endothelial cells and a slight edematous submucosa was detected. However, the mucosal layer showed moderate haemorrhagic condition with the presence of red blood cells.

\section{Group 5 - Effects of honey combined with ethanol extract of $\mathrm{C}$. odorata on gastric lesions produced by absolute ethanol com- bined with $\mathrm{HCl}$}

Pre-treatment with honey combined with ethanol extract of C. odorata, grossly showed reduction of $58.92 \%$ gastric lesions induced by absolute ethanol combined with $\mathrm{HCl}$. This pre-treatment indicated reliable cytoprotective effects. Histological examination showed fragile and eroded mucosa layers with moderate exfoliation of endothelial cells. In addition, edematous submucosa and red blood cells was detected.

\section{Group 6 - Effect of honey combined with cimetidine on gastric lesions produced by absolute ethanol combined with $\mathrm{HCl}$}

Oral administration of cimetidine combined with honey reduced the formation of gastric lesions that was produced by absolute ethanol combined with $\mathrm{HCl}$ at inhibition percentage of $56.55 \%$. This treatment showed cytoprotective effects. Histological examination showed intact mucosa layers with barely any exfoliation of endothelial cells. However, moderate edematous submucosa was detected with the appearance of marginated neutrophil around blood vessels and the superficial region of mucosal layer showed broad haemorrhagic condition.

\section{Discussion}

By calculating the inhibition percentage of gastric lesions, all the treatments were compared to ulcer control to measure the percentage that each treatment inhibited gastric lesions. All four treatments showed statistical significance when compared to ulcer control. Rats pre-treated with aqueous extract in combination with honey showed the highest inhibition percentage $(72.67 \%)$ followed by rats pretreated with alcoholic extract in combination with honey $(58.92 \%)$, rats pre-treated with cimetidine in 
combination with honey $(56.55 \%)$ and the lowest was for rats pre-treated with honey alone (46.74\%).

In this study, absolute ethanol combined with $\mathrm{HCl}$ was used as necrotizing agents to induce ulcer in rats. Ethanol and $\mathrm{HCl}$-induced gastric ulcers are commonly used for evaluation of anti-ulcer activity (19). Absolute ethanol and $\mathrm{HCl}$ rapidly penetrates the gastric mucosa $(20,2 \mathrm{I})$, which explains why 30 minutes was sufficient for developing gastric lesions in rats. In this study, oral administration of absolute ethanol combined with $\mathrm{HCl}$ produced extensive exfoliation of gastric mucosa cells which caused bleeding and inflammatory exudation. Ethanol causes haemorrhage lesions by inducing endothelin-I and constricts gastric vasculature, thereby causing stasis in blood flow (22).

Ethanol also incites vascular damage and alters mucosal microvascular permeability (7). It was suggested that depletion of non-protein sulfhydryl concentration and modulation of nitric oxide system are few of the factors contributing to ethanol-induced gastric lesions (6). Furthermore, reduction in glutathione level and production of oxygen-derived free radicals may contribute to ethanol-induced mucosal damage (7).

Subsequently, these factors stated above lead to the release of vasoactive products from mast cells (e.g. histamine), macrophages, polymorphonuclear leukocytes and other blood cells, which may lead to vascular injury, necrosis, and ulcer formation (20). Other roles of ethanol in generating ulcer also involve disturbances in gastric secretion, gastric mucus reduction (19) and causing submucosal edema (I).

In this study, in addition to evaluating the cytoprotective effects of honey alone, the effect of honey when combined with plant extracts and cimetidine were also evaluated. It was suggested that honey acted as vehicle, whereby honey attributed to the cytoprotective effects of $C$. odorata extracts. The same study also claimed that honey when combined with plant extracts, was more effective in its cytoprotective effect than the plant extracts alone (23). In addition, another reason for combining honey at $10 \% \mathrm{w} / \mathrm{w}$ with $C$. odorata extracts was because honey may help to reduce the toxic effect of the plant extract.

Honey alone showed moderate cytoprotective effects in protecting gastric mucosa against ethanol and $\mathrm{HCl}$. The cytoprotection mode of honey may mainly involve reduction in vascular permeability (7) and an increase in gastric mucosal blood flow (6). Inflammatory exudates levels were found to have decreased (24). In addition, the ability of honey to absorb edema, promote epithelialisation and improve the state of nutrition also contribute to the healing process $(6,24)$. Furthermore, honey also possesses antioxidant properties that abolish the increment of endothelial cell permeability (7). This may be the key factor of honey in preventing extensive exfoliation of mucosal cells induced by ethanol and $\mathrm{HCl}$.

C. odorata is a popular herbal remedy in treating wounds, burns and skin infection (13). Although C. odorata has not been well established in promoting cytoprotection toward gastric mucosa, many properties of $C$. odorata in wound healing can be applied in elucidating the mode of protection produced by $C$. odorata in this study.

Polysaccharides are general constituents of Asteraceae family, which holds many therapeutic properties. Alginic acid (heterogeneous polysaccharides) was suggested to form gel layer and acts as barrier against excessive $\mathrm{pH}$ changes and thus protects the gastric mucosa (25). It is speculated that polysaccharide constituents contribute to the production of cytoprotective effects in C. odorata.

The aqueous extracts of $C$. odorata in this study significantly inhibited the action of ethanol in combination with $\mathrm{HCl}$ in inducing ulcer. The cytoprotective effect is statistically significant when compared to honey alone, which showed that the cytoprotective effects of aqueous extracts of $C$. odorata combined with honey was not merely due to the honey only. It was observed that exfoliation of gastric mucosa cells was mild and only occurred at the superficial layer. This may be due to the powerful antioxidant (17) and anti-inflammatory (14) properties of C. odorata, which must have prevented the decrease in mucosal cells and vascular permeability induced by ethanol and $\mathrm{HCl}$.

The capacity of $C$. odorata to stimulate the expression of many essential proteins (I3) such as increasing endogenous prostaglandin may also contribute to decrease in vascular permeability (26). Furthermore, the extracts of $C$. odorata are known to increase proliferation of epithelial cells (17) and may be involved in the healing process of gastric mucosa. The presence of red blood cells was detected and this may be due to enhancement of haemostasis by $C$. odorata extract to stop bleeding (16).

Compared to the aqueous extract of $C$. odorata, the ethanol extract of $C$. odorata only showed modest cytoprotective effects in preventing gastric damage induced by absolute ethanol and $\mathrm{HCl}$. Even though exfoliations of gastric mucosal cells were moderate, inflammatory exudates were found particularly in the 
mucosal and submucosa layers, which may explain the fragile and eroded mucosa layers. This may due to a slight increase of vascular and mucosal cells permeability (27). Furthermore, red blood cells were also detected in the mucosal layers and may also be due to the same reason (20).

Even though the ethanolic method of extraction was also used to extract $C$. odorata in this study, heating the plant in water has actually been the traditional Vietnamese method of preparing $C$. odorata extracts. Furthermore, chromatography evaluation indicated that the compounds found in $C$. odorata extracts such as flavonoids and other phenolic compounds are soluble in hot water. Therefore, it was thought that aqueous extraction method was the best way to obtain the constituents of $C$. odorata (I6), and this may be the reason why the aqueous extract of $C$. odorata was more effective in inhibiting gastric lesions induced by ethanol and $\mathrm{HCl}$ compared to the ethanolic extract of $C$. odorata in this study. However, the difference between aqueous extract of $C$. odorata and ethanolic extracts of $C$. odorata in generating cytoprotective effects was not statistically significant. This was possibly due to the small number of rats used in the study. Furthermore, pre-treatment with ethanolic extract of C. odorata combined with honey was not statistically significant compared to pre-treatment with honey alone (Group 3) and neither was it significant compared to pre-treated with cimetidine combined with honey (Group 6).

Histological examination of the group that was pretreated with cimetidine combined with honey showed a rather intact mucosal layer even though a broad superficial region of mucosa layer appeared haemorrhagic. Cimetidine is well known for its effectiveness in reducing gastric acidity (28) and this may be the reason behind the intact mucosa layer in this group. A study suggested that cimetidine possesses direct cytoprotective effects on the gastric mucosa (29). However, the dose of cimetidine used in that study was higher $\left(300 \mathrm{mg} \mathrm{kg}^{-1}\right)$ compared to the dose used in the present study, $50 \mathrm{mg} \mathrm{kg}$. This may explain the haemorrhages at the superficial region of mucosa layer and also the presence of edematous submucosa (27). The pre-treatment of cimetidine combined with honey was statistically significant compared to pretreatment of honey alone.

\section{Conclusion}

In conclusion, honey alone, aqueous and ethanol extracts of $C$. odorata and cimetidine possess cytoprotective properties. Through histological examination, it was speculated that the cytoprotective effects observed in this study include decreased exfoliation of mucosal cells, reduced inflammatory exudates, minimizing mucosal cells and vascular permeability chances.

Furthermore, in this study, there was no statistical significance between aqueous and ethanolic extracts of $C$. odorata in promoting cytoprotective effects. Nevertheless, both extracts of $C$. odorata were able to deliver satisfying cytoprotective effects in reducing gastric mucosal lesions induced by absolute ethanol combined with $\mathrm{HCl}$.

Further investigation of $C$. odorata in inducing cytoprotectiveness needs to be carried out because it might be beneficial in treating a variety of diseases that are related to gastric mucosal injury.

However, for human consumption, further pharmacological tests need to be conducted to determine appropriate doses for humans and to uncover any adverse effects which may arise from administration of C. odorata.

\section{References}

I. Robert A., Nezamis JE, Lancaster C, et al. Cytoprotection by prostaglandins in rats. Prevention of gastric necrosis produced by alcohol, $\mathrm{HCL}, \mathrm{NaOH}$, Hypertonic $\mathrm{NaCl}$, and thermal injury. Gastroenterology 1979; 77: 433-443.

2. Guha S, Kaunitz J. Gastroduodenal mucosal defense: an integrated protective response [Stomach and duodenum]. Current Opinion in Gastroenterology 2002; 18(6): 650-657.

3. Sener-Muratoglu G, Paskaloglu K, Arbak S, et al. Protective effect of famotidine, omeprazole, and melatonin against acetylsalicylic acid-induced gastric damage in rats [Esophageal, Gastric, and Duodenal Disorders]. Dig Dis Sci 200I; 46(2): 318-330.

4. Kawabata A, Kinoshita M, Nishikawa H, et al. The protease-activated receptor-2 agonist induces gastric mucus secretion and mucosal cytoprotection [Hormones and Metabolism]. J Clin Invest 200I; 107(II): |443-1450.

5. Bagchi D, Mcginn Thomas R, Ye X, et al. Mechanism of gastroprotection by bismuth subsalicylate against chemically induced oxidative stress in cultured human gastric mucosal cells [esophageal, gastric, and duodenal disorders]. Dig Dis Sci 1999; 44(12): 2419-2428.

6. Gharzouli K, Gharzouli A, Amira S, et al. Prevention of ethanol-induced gastric lesions in rats by natural honey and glucose-fructose-sucrose-maltose mixture. Pharmacol Res 1999; 39(2). 
7. Mobarok Ali ATM, Al-Swayeh OA. Natural honey prevents ethanol-induced increased vascular permeability changes in the rat stomach.J Ethnopharmacol 1997; 55: 23।-238.

8. Ambika SR, Jayachandra. Influence of light on seed germination in Eupatorium odoratum L. Indian Forester 1980; 106: 637-640.

9. Irobi ON. Activities of Chromolaena odorata (Compositae) leaf extract against Pseudomonas aeruginosa and Streptococcus faecalis. J Ethnopharmacol 1992; 37:81-83.

10. Bennett FD, Rao VP. Distribution of an introduced weed Eupatorium odoratum L. in Asia and Africa and possibilities of its biological control. PANS. (C) 1968; I4: 277-28I.

II. Rai SN. Eupatorium and weedicides. Indian Forester 1976; 102: 449-454.

12. Sajise PE, Palis RK, Norcio NV, et al. The Biology C. odorata L. King and Robinson. Flowering behaviour pattern of growth and nitrate metabolism. Phil. Weed. Sci. Bull. 1974; I: 17-24.

13. Phan TT, Allen J, Hughes MA, et al. Upregulation of adhesion complex proteins and fibronectin by human keratinocytes treated with an aqueous extract from leaves of Chromolaena odorata (Eupolin). Eur J Dermatol 2000; 10(7): 522.

14. Olajide OA, Taiwo OB, Soyannwo OO, et al. Antiinflammatory, antipyretic and antispasmodic properties of Chromolaena odorata. Pharmaceutical Biology 2000; 38(5): 367-370.

15. Ambika SR, Jayachandra, editor. Eupatorium odoratum L. in plantation - An allelopath or a growth promoter? Proceedings of the 5 th annual symposium on plantation crops; 1982 Dec I5- I8; CPCRI, Kasaragod; 1982.

16. Phan TT, Hughes MA, Cherry GW. Enhanced proliferation of fibroblasts and endothelial cells treated with an extract of the leaves of Chromolaena odorata (eupolin), an herbal remedy for treating wounds. Plast Reconstr Surg 1998; I0I(3): 756-765.

17. Phan TT, Wang L, See P, et al. Phenolic compounds of Chromolaena odorata protect cultured skin cells from oxidative damage: implication for cutaneous wound healing. Bio Pharm Bull 200 I; 24(I2): I373-9.
18. Tan PV, Nditafon GN, Yewah MP, et al. Eremomastax speciosa: Effect of the leaf aqueous extract on ulcer formation and gastric secretion in rats. J Ethnopharmacol 1996, 54: I39-| 42.

19. Suja Pandian R, Anuradha CV, Viswanathan P. Gastroprotection effect of fenugreek seeds (Trigonella foenum graecum) on experimental gastric ulcer in rats. J Ethnopharmacol 2002; 81: 393-397.

20. Bilici D, BanoGlu ZN, Kiziltunç A, et al. Antioxidant effect of T-type calcium channel blockers in gastric injury [esophageal, gastric, and duodenal disorders]. Dig Dis Sci 2002; 47(4): 850-855.

21. Tan PV, Dimo T, Dongo E. Effects of methanol, cyclohexane and methylene chloride extracts of Bidens pilosa on various gastric ulcer models in rats.J Ethnopharmacol 2000; 73: 4I5-42I.

22. Hiroaki M, Sunao K, Shingo T, et al. Combination therapy of ecabet sodium and cimetidine compared with cimetidine alone for gastric ulcer: Prospective randomized multicentre study [Gastric acid suppression]. J Gastroenterol and Hepatol 2003; 18(9): 1029-1033.

23. Gurbuz I, Akyuz C, Yesilada E, et al. Anti-ulcerogenic effect of Momordica charantia L. fruits on various ulcer models in rats. J Ethnopharmacol 2000; 71: 77-82.

24. Dunford C, Cooper R, Molan P, et al. The use of honey in wound management [Art\&Science: Tissue Viability]. Nurs Stand 2000; I5(II): 63-68.

25. Wiart C, Kumar A. Practical Handbook of Pharmacognosy. Preliminary techniques of identification of crude drugs of plant origin. Selangor: Prentice Hall; 200I.

26. Borrelli F, Izzo AA. The plant kingdom as a source of anti-ulcer remedies. Phytother Res 2000; I4(8): 58I-9I.

27. Chen RH, Chau HL. Protective effect of cimetidine on tannic acid-induced gastric damage in Rats. J Pharm Pharmacol 199|; 43: 559-563.

28. Katzung BG. Basic and Clinical Pharmacology. 7th ed. New York: McGraw-Hill; 1998.

29. Mozsik G, Morn F, Nagy L, et al. Evidence of the gastric cytoprotective effects of vitamin A, atropine, and cimetidine on the development of gastric mucosal damage produced by administration of indomethacin in healthy subjects. Int J Tissue React. 1986; 8(I): 85-90. 